\title{
Prevención de dificultades lectoras y escritoras en Educación Infantil.
}

(Prevention of reading and writing difficulties in childhood education.)

\author{
Marta Luque Cruz \\ Universidad de Jaén, España.
}

Fecha recepción: 30-05-2018

Páginas 56-65

Fecha aceptación: 30-06-2018

\section{Resumen.}

El presente trabajo se ha realizado con la finalidad de investigar el conocimiento que poseen los maestros y maestras de Educación Infantil sobre cómo identificar, prevenir y actuar con alumnos con dificultades lectoescritoras. Para ello, hemos recopilado información sobre las competencias lectoras y escritoras para entender mejor su adquisición, cómo trabaja el cerebro cuando lee o escribe, qué teorías existen sobre la lectura o escritura, etc. Además, se han investigado las posibles dificultades o retrasos que puede presentar el alumnado a la hora de leer y escribir.

Posteriormente, se ha llevado a cabo dicha investigación mediante una escala Likert de cuarenta ítems con una muestra de 40 docentes de aulas de centros andaluces. Los resultados muestran la falta de preparación y conocimientos que presentan en la actualidad los docentes de infantil con respecto a las dificultades lectoescritoras y su prevención en las aulas.

Palabras clave: trastorno del aprendizaje; lectoescritura; dislexia; disgrafía; disortografía

\begin{abstract}
.
The present work has been done by the purpose of investigating the knowledge that there possess the teachers of Childhood Education on how to identify, to anticipate and to act with children with literacy difficulties. For it, we have compiled information about the reading and writing competitions to understand better his acquisition, how the brain works when it reads or writes what theories exist on the reading or writing... In addition, there have been investigated the possible difficulties or retardation that the students can present at the moment of reading and writing.

Later, the above mentioned investigation has been carried out by means of a scale Likert of forty articles by a sample of 40 teachers of classrooms of Andalusian centers. The results show the lack of preparation and knowledge that the teachers of Childhood Education have over of the literacy difficulties and his prevention in the classrooms.
\end{abstract}

Keywords: learning disabilities; literacy; dyslexia; dysgraphia; dysorthographia 


\section{1.-Introducción.}

El siguiente documento se ha elaborado como resultado de un proceso de investigación sobre las dificultades y trastornos de aprendizaje de la lectura y la escritura y su prevención en el último nivel de Educación Infantil.

Para afrontar el tema planteado, hemos incluido dentro del marco teórico: conceptos, clasificaciones, teorías, métodos, etc., que sirvan como apoyo, para comprender en qué consisten las habilidades de lectura y escritura, sus posibles dificultades y cómo se puede detectar al alumnado con dichas dificultades.

Además, para dar respuesta a todas estas cuestiones y conocer la opinión de los profesionales que se enfrentan día a día con estas dificultades, hemos estimado oportuno realizar una investigación a maestros de diferentes centros de la provincia de Jaén. Dicha investigación se ha llevado a cabo con una escala Likert dividida en cuatro dimensiones y con un total de cuarenta ítems. La escala Likert constituye una de las técnicas de medida de creencias, preferencias y actitudes más utilizada por los científicos de la conducta. En palabras de Dawes (1975) (referido en Cañadas y Sánchez, 1998), se trata de "la omnipresente escala de clasificación" (p. 115).

Los resultados de nuestra investigación nos proporcionan datos concluyentes para determinar que en la actualidad los maestros de educación infantil no se encuentran capacitados para trabajar en el aula con niños con problemas lectores y escritores, puesto que no son capaces, según los datos de nuestra investigación, de detectar dichas dificultades.

\section{2.-Marco teórico.}

\section{1.-Educación Infantil.}

Durante la etapa de Educación Infantil no es necesario que los niños/as adquieran su habilidad lectora y escritora, puesto que es una competencia que pertenece al currículum de Educación Primaria. Sin embargo, tal y como aparece recogido en la legislación española (BOJA núm. 169), la educación infantil contribuirá a desarrollar en los niños y niñas las capacidades que les permitan "Aproximarse a la lectura y escritura en situaciones de la vida cotidiana a través de textos relacionados con la vida cotidiana, valorando el lenguaje escrito como instrumento de comunicación, representación y disfrute." (Artículo 13 de la Ley Orgánica 2/2006, 3 de mayo, p.22).

\section{2.-Lectura.}

La lectura, para Solé (1992) es un proceso muy complejo que conlleva muchas funciones cognitivas y sensoriales, entre las que podemos encontrar: la atención y concentración, la conciencia fonológica, la conciencia ortográfica, la conciencia de las palabras, la conciencia sintáctica, la decodificación rápida, la comprensión verbal y la conciencia pragmática. Según Jiménez (1989) los métodos de lectura se pueden agrupar en dos tipos: métodos sintéticos. Que a su vez se pueden dividir en tres 
métodos: alfabético, fónico y silábico; métodos analíticos o globales. Que se dividen en dos métodos: léxicos y globales-naturales.

\section{3.-Escritura.}

Solé (2012), describe al escritor como aquel que realiza un acto donde expresa sus ideas y conocimientos a través de un sistema alfabético, en el que hace uso de uno 0 varios niveles de la lengua escrita: nivel ejecutivo, nivel funcional, nivel instrumental y nivel epistémico 0 crítico.

Escribir es una actividad muy compleja que implica poner en marcha muchos procesos simultáneamente. Existen diferentes modelos que tratan de explicar los procesos cognitivos implicados en la escritura. Cuetos (1991) describe los procesos cognitivos implicados en la escritura. Algunos requieren de una gran carga cognitiva (atencional, memorística, de razonamiento,...), y otros son más simples. A cada uno de estos procesos lo denomina módulo. Existen cuatro módulos: módulo de planificación, módulo sintáctico, módulo léxico y módulo motor. Los dos primeros módulos (planificación y sintáctico) son más complejos y los dos últimos más sencillos.

El acto de escribir exige el funcionamiento de múltiples estructuras neurológicas. Gómez y Gómez (1985) establecen que para el procedimiento de la escritura se deben tener en cuenta los siguientes pasos: primero, la evocación interior de la imagen auditiva y motriz del fonema correspondiente al grafema; segundo, la transformación de la imagen auditivo-motriz del fonema en la imagen óptica del grafema; tercero, la generación de imágenes motrices o esbozos mentales de aquellos movimientos y posturas, los cuales permitirán ejecutar la escritura; cuarto, la percepción óptica del espacio escritural, en la persona que desea trazar una letra; y por último, se produce el trazado real del grafema.

\section{4.-Dificultades lectoras y escritoras.}

Según Romero y Castaño (2016), un porcentaje importante del alumnado presenta dificultades en la adquisición de la lectura. Por ello, resulta clave detectar e intervenir tempranamente las dificultades de aprendizaje lectoras para lograr un mayor beneficio tanto académico como emocional. En los últimos años se ha ampliado la investigación en torno a las variables predictoras de la lectura y escritura, dando la posibilidad de detectar precozmente al alumnado que presenta dificultades en esas habilidades y así poder intervenir en las mismas. Entre las variables estudiadas, el procesamiento fonológico resulta ser el mejor predictor de la adquisición lectora. Según investigaciones de autores como Balado, Rivas, Torres y Taboada (2017), las dificultades lectoescritoras afectan a un 5-10\% de los niños en edad escolar.

\subsection{1.-Retrasos.}


Según Cardona y Cadavid (2013), el término de retraso lector surgió "para dar cuenta de aquellos casos que ante un desarrollo psicológico esperado para su edad y escolaridad presentaban una curva de adquisición de la lectura, por lo menos, dos años más demorada a la observada en sus pares" (p.260).

\subsection{2.-Dislexia.}

Rivas y Fernández (2002), definen la dislexia como "una dificultad para la distinción y memorización de letras o grupos de letras, falta de orden y ritmo en la colocación y mala estructuración de las fases, afectando tanto a la lectura como a la escritura del individuo" (p. 24). La dislexia lleva ligada una gran variedad de características que pueden agruparse en dos grandes bloques: manifestaciones conductuales (ansiedad, inseguridad, atención inestable...) y manifestaciones escolares (inversiones de letras o palabras, caligrafía deficiente, dificultad para diferenciar izquierda y derecha...). Dejerine (citado en Lores, Calzadilla, Hernández, Noguera y Díaz, 2014) planteó que los pacientes disléxicos presentaban una lesión en la región temporal posterior del hemisferio izquierdo, donde entran en contigüidad los lóbulos occipital y parietal. De esta forma, inicialmente la dislexia fue entendida como un trastorno neurológico específico cuyo origen está en un traumatismo cerebral adquirido. Cabrera (2010) (citado en Cedeño, Persia y Puelles, 2018), expone que "si bien es cierto que pueden existir múltiples causas de la dislexia, hay dos factores fundamentales que no se pueden obviar: los neurofisiológicos y los conflictos psíquicos" (p.148).

\subsection{3.-Disgrafía.}

Según Hernández (2004), "el término disgrafía se utiliza ampliamente para hacer referencia a un conjunto de trastornos de aprendizaje del lenguaje en el niño que afecta, sobre todo, al lenguaje escrito" (p.35). Los síntomas de la disgrafía suelen ser la confusión de direcciones, escritura y deletreo deteriorados, deficiencias de percepción visual, anomalías de la dominancia cerebral, fragilidad en el almacenamiento de contenidos en la memoria, disfunciones motoras, demoras en la maduración, desarrollo tardío del habla, disfunciones neurológicas y retrasos en el lenguaje. Hay cierto tipo de asociación entre disgrafía y un funcionamiento neurológico anormal o diferente.

\subsection{4.-Disortografía.}

Portellano (1985) define la disortografía como la incapacidad de estructurar gramaticalmente el lenguaje y que generalmente, va asociada a los trastornos de lectura (dislexia evolutiva). Según Rivas y Fernández (2002), la disortografía se caracteriza por una serie de errores sistemáticos en la escritura y la ortografía, entre los que podemos encontrar: errores de carácter lingüístico-perceptivo, de carácter visoespacial, de carácter visoauditivo, con relación al contenido y referidos a las reglas de ortografía.

\section{3.-Diseño de la investigación.}


De acuerdo con los objetivos planteados, se intenta delimitar el método de estudio desde la investigación en educación. Para ello consideramos necesario definir, en primera instancia, el concepto de método. Según Bisquerra (1989), "los métodos de investigación constituyen el camino para llegar al conocimiento científico; son un procedimiento o conjunto de procedimientos que sirven de instrumento para alcanzar los fines de la investigación" (p. 55).

Nuestra investigación es de naturaleza exploratoria y descriptiva, adoptaremos una metodología cuantitativa, imprescindible, tanto para valorar los resultados obtenidos como para relacionar los mismos.

\section{3.-Objetivos.}

\section{1.-General.}

Analizar las dificultades lectoras y escritoras y su prevención en Educación Infantil.

\section{2.-Específicos.}

- Determinar la importancia que los docentes le dan a la lectura en Educación Infantil.

- Constatar la importancia que los docentes le dan a la escritura en Educación Infantil.

- Mostrar el conocimiento que los docentes tienen de las dificultades lectoras en Educación Infantil.

- Exponer el conocimiento que los docentes tienen de las dificultades escritoras en Educación Infantil.

\section{4.-Análisis e interpretación de los datos.}

A continuación, mostraremos un ítem de cada dimensión de nuestra investigación e interpretaremos los resultados obtenidos.

\section{1.-La lectura en Educación Infantil.}

Gráfico 1: Es muy importante el aprendizaje de la lectura en Educación Infantil. 


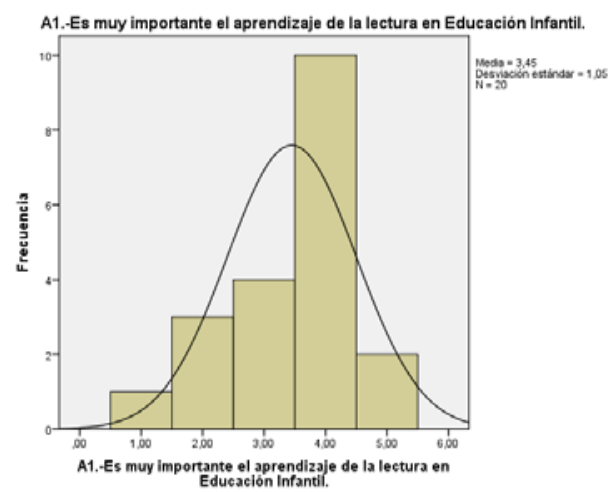

Fuente: elaboración propia (2018).

En este primer ítem preguntábamos a los encuestados si consideraban importante el aprendizaje de la lectura en Educación Infantil. En esta gráfica podemos apreciar el valor de la media aritmética, que es el valor característico de una serie de datos cuantitativos. En nuestro caso la $\bar{x}=3,45$. En nuestras escalas el encuestado debe de seleccionar su nivel de acuerdo con respecto a lo que se pregunta (donde 1 es muy en desacuerdo, 2 es en desacuerdo, 3 es indiferente, 4 es de acuerdo y 5 es muy de acuerdo). Lo que indica en este caso, que la mayoría de los docentes se muestran indiferentes ante el aprendizaje de la lectura en Educación Infantil. Por lo que podemos deducir que no consideran necesaria la adquisición de la habilidad lectora en esta etapa.

\section{2.-La escritura en Educación Infantil.}

\section{Gráfico 2}

İtem: Me gusta trabajar la capacidad escritora en el aula desde el primer nivel.

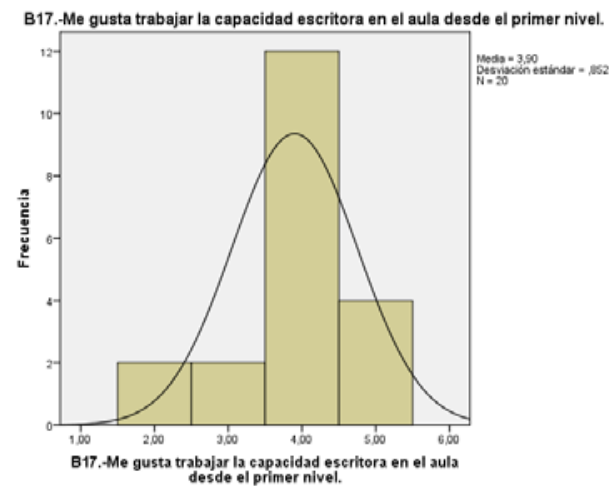

Fuente: elaboración propia (2018).

Ante la afirmación del siguiente ítem se les preguntaba a los docentes si les gustaba trabajar la capacidad escritora en el aula desde el primer nivel. En la gráfica se 
observa claramente como la mayoría de los encuestados se muestran de acuerdo con dicho enunciado. Siendo la media aritmética de 3,90.

Este resultado coincide con el obtenido en el ítem 7 (me gusta trabajar la capacidad lectora en el aula desde el primer nivel), lo que quiere decir, que la mayoría de los docentes coinciden en empezar a trabajar las capacidades lectoras y escritoras desde el primer nivel de Educación Infantil, es decir, desde los tres años.

\section{3.-Dificultades lectoras en Educación Infantil.}

\section{Gráfico 3}

Ítem: El retraso lector es consecuencia de un coeficiente intelectual bajo.

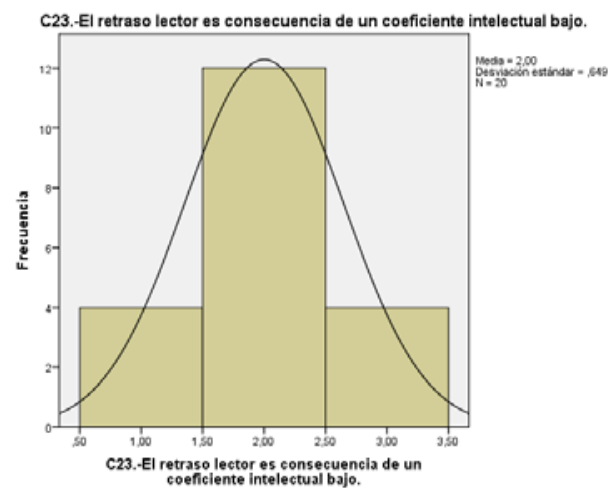

Fuente: elaboración propia (2018).

El siguiente ítem afirmaba que el retraso lector es consecuencia de un coeficiente intelectual bajo. Con lo que los encuestados se mostraban en desacuerdo con una media aritmética de 2,00.

Esta afirmación, según Bravo, Villalón y Orellana (2006) es verdadera, por lo que nuestros docentes habrían errado al mostrarse en desacuerdo.

\section{4.-Dificultades escritoras en Educación Infantil.}

\section{Gráfico 4}

Ítem: Estoy totalmente capacitado/a para trabajar en el aula con niños/as con dificultades escritoras. 


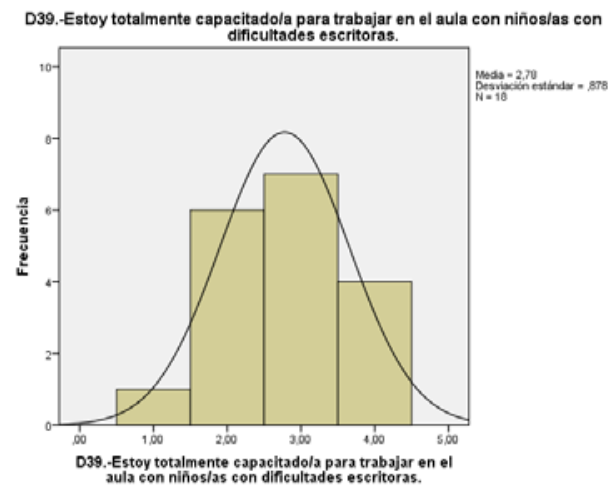

Fuente: elaboración propia (2018).

En este ítem se preguntaba a los docentes si se veían totalmente capacitados para trabajar en el aula con niños con dificultades escritoras. A lo que los encuestados respondieron con una media aritmética de 2,78, que se mostraban indiferentes ante dicha pregunta.

Suponemos que puede deberse a la falta de conocimiento que tienen los docentes sobre las dificultades escritoras, de manera que no sabrían si serían o no capaces de trabajar con este tipo de alumnado. Solo cuatro de los encuestados se ven capacitados y otros seis confiesan que no lo estarían.

\section{5.-Conclusiones.}

La elaboración de este trabajo ha supuesto, en primer lugar, una toma de conciencia sobre la importancia que tiene el conocer los tipos de dificultades lectoras y escritoras que puede presentar el alumnado. Para ello ha sido necesario informarnos acerca de las competencias lectoras y escritoras, qué procesos cognitivos intervienen en el aprendizaje, qué teorías y métodos existen y el funcionamiento del cerebro; además de los tipos de dificultades que existen en la lectoescritura, sus etiologías, características y clasificaciones.

En segundo lugar, hemos de señalar la necesidad de concienciar a los docentes de Educación Infantil de la importancia que tiene la detección temprana de los trastornos en la lectura y la escritura, puesto que una detección precoz puede evitar y corregir en gran medida dichos trastornos y prevenir el fracaso escolar en las aulas.

A través de nuestra investigación hemos podido comprobar que actualmente los docentes de infantil no están capacitados para llevar a cabo esta tarea debido a la falta de preparación que tienen sobre las áreas de los trastornos de la lectura y la escritura. Por lo que consideramos necesaria una actuación urgente para formar al profesorado y proporcionarles las herramientas necesarias para que puedan detectar las dificultades lectoescritoras desde los primeros años de escolarización. 


\section{6.-Referencias.}

Balado, C., Rivas, R.M., Torres, S., y Taboada, E.M. (2017). Evaluación neuropsicológica de las dificultades de aprendizaje lectoescritoras en el aula. Revista de estudios e investigación en psicología y educación, (1). doi: https://doi.org/10.17979/reipe.2017.0.01.2485

Bisquerra, R. (1989). Métodos de investigación educativa. Barcelona: CEAC.

Bravo, L., \& Villalón, M., \& Orellana, E. (2006). Predictibilidad del rendimiento en la lectura: una investigación de seguimiento entre primer y tercer año. Revista Latinoamericana de Psicología, 38 (1), 9-20.

Cardona, M., y Cadavid, N. (2013). Perfil lector de niños con y sin retraso lector en la ciudad de Cali (Colombia). Psicología desde el Caribe, 30 (2), 257-275.

Carvajal, A., Centeno, C., Watson, R., Martínez, M., y Sanz, A. (2011). ¿Cómo validar un instrumento de medida de la salud? Anales del Sistema Sanitario de Navarra, 34 (1), 63-72.

Cañadas, I., y Sánchez, A. (1998). Categorías de respuesta en escalas tipo likert. Psicothema, 10 (3), 623-631.

Cedeño, C., Persia, L. y Puelles, R. (2018) Conocimientos básicos sobre dislexia. Cejudo, A. y Corchuelo, C. (Coord.), La evaluación psicopedagógica a debate. Reflexiones y experiencias de profesionales de titulaciones educativas (pp.146-159). Sevilla: AFOE.

Cuetos, F. (1991). Psicología de la escritura: diagnóstico y tratamiento de los trastornos de escritura. Madrid: S.A. Escuela Española.

Gómez, P. y Gómez, M. (1985). Lenguaje y cerebro. Valladolid: Universidad de Valladolid. Secretariado de Publicaciones E I.

Hernández, A. (2004). Los errores lingüísticos. Valencia: Nau Llibres.

Jiménez, J. (1989). La prevención de dificultades en el aprendizaje de la lectoescritura. Madrid: CEPE.

Lores, I., Calzadilla, O., Hernández, I., Noguera, K., y Díaz, F. (2014). La ayuda logopédica a niños con manifestaciones de dislexia y disgrafía. Correo Científico Médico, 18(1), 18-24.

Portellano, J. (1985). Disgrafía. Concepto diagnóstico y tratamiento de los trastornos de escritura. Madrid: CEPE. 
Rivas, M., y Fernández, P. (2002). Dislexia, disortografía y disgrafía. Madrid: Pirámide.

Romero, A., y Castaño, C. (2016). Prevenir las dificultades lectoras: diseño y evaluación de un software educativo. Pixel-Bit. Revista de Medios y Educación, (49), 207-223.

Solé, I. (1992). Estrategias de lectura. Barcelona: Editorial Graó.

Solé, I. (2012). Competencia lectora y aprendizaje. Revista Iberoamericana de Educación (59), 43-61. 